\title{
Information use on Decision-making Process of Administrative Staff of Federal University of Agriculture Abeokuta, Ogun State, Nigeria
}

\author{
Vincent E. Unegbu*, Foyibo Ekiverere Runo \\ Babcock University, Ikeja Lagos, Nigeria \\ *vinunegbu@yahoo.com
}

\begin{abstract}
Information is vital in decision making; and bad decisions most of the times are as a result of lack of adequate information. This research examined the administrative staff's use of information in their decision making process in Federal University of Agriculture, Abeokuta. The descriptive survey, total enumeration technique, and a well-structured questionnaire were used to obtain data. Most of the administrative staff members were fully aware of how the use of information aids in administrative decisions. The most frequently consulted information sources were internal memo, minutes of meeting, schedules of meeting, past conference papers and dictionaries. The reasons for administrative staff's use of information were according to confronting issues like scheduling appointments, calling up meetings, and recruiting new staff. The use of mobile phones by administrative staff should be encouraged since the administrators could receive messages anywhere and at any point in time to make both individual and administrative decisions.
\end{abstract}

Key Words: Information use; Information source; Decision making; Administrative staff

\section{Introduction}

Information use is one of the three important elements of information behavior. The other two are information need and information seeking. Information use drives all other information behaviors since it represents the ultimate purpose for which information is needed and sought. A University makes decisions, prepares plans and controls activities by using information obtained from various sources. Good information should be relevant for its purpose, sufficiently accurate, reliable and targeted to the right person(s) and completely enough to solve inherent administrative problems. It is also communicated in time for its purpose, contains the right level of detail and is communicated through an appropriate channel. According to Birnbaum (1998), educational administration is very frustrating because, almost always, solutions to problems create new problems. One way of attempting to increase administrative capability is to resolve dilemmas by seeking more rational ways of making decisions, more structured methods of problem-solving or greater authority in overcoming the resistant forces of participants. The administrative staff would be frustrated if information contains data that is irrelevant to the task in hand. To obtain information that is $100 \%$ accurate is usually unrealistic as it is likely to be too expensive to produce on time. Information should contain all the details required by the administrative staff, otherwise, it may not be useful as the basis for making decision. To meet all the needs of the situation, the administrative staff has to source information from a variety of sources. Information should be in a form that is short enough as to allow for easy and fast examination and use, and should contain the best amount of details consistent with effective decision making. Information must be available and accessible on time for its required purpose. For information to have value it must be used, and for it to be used, the administrative staff must have confidence in the source. The decision-making process involves many steps such as: defining the problem, identifying limiting factors, developing potential alternatives, analyzing the alternatives, selecting the best alternative, implementing the decision, and establishing a control and evaluation system. The decision-making process begins with identifying the real problem. The accurate definition of the problem affects all the steps that follow. If the problem is inaccurately defined, every step in the decision-making process will be based on an incorrect starting point. 
One way that administrative staff can help determine the true problem in a situation is by identifying the problem separately from its symptoms. All managers want to make the best decisions. To do so, administrative staff needs to have the ideal resources which include information, time, personnel, equipment, and supplies; and identify any limiting factors. Thus, managers should think through and investigate several alternative solutions to a single problem before making any decision. One of the best known methods for developing alternatives is through brainstorming, where a group works together to generate ideas and alternative solutions. Though it is said that it is better to make a bad decision than not to make any at all; and a contributor in a blug said that "a wrong decision indicates a decision-making process was entailed and, therefore, is better than no decision having been made" (Rey (2008); Parree (2011); Silviablue (2009). It is also noteworthy to understand that "Managerial decision-making affects employee morale and has a direct effect on employee retention. Bad decision-making can not only cause problems with the employees, but it can also have a negative effect on the company's bottom line" (Anderson, 2013). When making decisions in any organization or institution, it is better that the decision be based on enough information and be devoid of bias. A biased decision may lead to unprecedented catastrophe in an organization. As Anderson (2013) puts it, "A manager's bias, when used in the decision-making process, can put the wrong employees in positions of authority and create a lack of confidence among other employees". This may result in a lack of trust in the manager or administrator by the subordinates. To avoid bias and wrong decisions that may adversely affect institutions, administrators should be adequately informed on pending matters before decisions are taken. To take a good decision, information is vital. To this effect, this paper sought to survey the use of information by the administrative staff of Federal University of Agriculture, Abeokuta, Nigeria.

Brief History of the Federal University of Agriculture, Abeokuta: The Federal University of Agriculture, Abeokuta (FUNAAB) is one of the three Universities of Agriculture that were established by the federal government of Nigeria on January 1, 1988. The University's permanent site is located $20 \mathrm{~km}$ away from the temporary site and shares boundary with Ogun-Oshun River Basin Development Authority on the AbeokutaIbadan Road. It is located at Alabata in Abeokuta, capital of Ogun State, Nigeria. The University has a total population of 6000 students comprising of 4500 undergraduate and 1500 post-graduate students, as at the year 2011. The Federal University of Agriculture, Abeokuta started off from the old Campus of Abeokuta Grammar School, Isale-Igbein near the city centre. It completed its movement to its permanent site along Alabata Road in 1997, in what has been termed the fastest pace of permanent site development in the history of Nigerian university system. Federal University of Agriculture, Abeokuta (FUNAAB) has administrative staff strength of 576. It has eight schools or faculties. (Source: Official Website of Federal University of Agriculture Abeokuta, www.unaab.edu.ng, 2012).

Statement of Problem: Information use is an integral part of our daily lives and as a result of this, information can be used to make improved decisions and ultimately improve the outcome or performance of the university administration. However, decisions are made in difficult, competitive and dynamic environments. From previous research findings, there is bound to be inappropriate decision making, poor priority of needs and scheduling of activities if the relevant information that is required is not available at the appropriate time, hence, the administrative staff will not be efficient and effective in his administrative duties in Nigerian Universities like Federal University of Agriculture, Abeokuta. Based on this fact, the study tends to investigate how efficient Administrative Staff of Federal University of Agriculture, Abeokuta uses information to make administrative decisions in the University.

The general objective of this study was to investigate how information use influenced the decision making process of Administrative Staff of Federal University of Agriculture Abeokuta.

The specific objectives are to:

- Determine the sources of information used by the administrative staff of Federal University of Agriculture, Abeokuta.

- Know the reasons for information use by administrative staff of Federal University of Agriculture, Abeokuta. 
- Survey the influence of information use on decision making process of administrative staff of Federal University of Agriculture, Abeokuta.

\section{Research Questions}

- What are the sources of information used by administrative staff of Federal University of Agriculture, Abeokuta?

- For what reasons do the administrative staff of Federal University of Agriculture, Abeokuta use information?

- What influence does information use have on decision making process of the administrative staff of Federal University of Agriculture, Abeokuta?

Significance of the Study: Organizations cannot survive without information, and without the use of information accurate decisions cannot be made. The use of information increases knowledge and reduces uncertainty. The significance of this study is to create awareness of the administrative staff in the Federal University of Agriculture, Abeokuta on how important it is to have a broad understanding of the influence of the use of information on decision making.

\section{Definition of Operational Terms}

Decision making process: Decision making process is a string of actions to be followed before important decisions are made by any Administrative staff.

Information Utilization: Information utilization is making actual or concrete use of information acquired from any or different sources. The acquired information from various sources is used for the purpose of making decisions or accomplishing a specific task by the administrative staff.

Administrative Staff: An administrative staff is an individual or person that carries out managerial, directorial and executive functions of a department, unit or several units in an organization in order to support the goals and objectives of his/her employing organization or institution.

\section{Literature Review}

The critical success factor for successful management is the strategic use of information; and a positive correlation has been found between management success and effective information needs assessment, gathering and use (Goodman, 1993). Relevant and timely information allows administrative staff to make accurate decisions while irrelevant information on the other hand makes decision making difficult. It is therefore crucial that managers are aware of what information that would be required, how the information is acquired and how best to maximize the use of information for decision making purposes in order to survive in today's information intensive environment. The following are subheadings for literature review: Sources of information, Information needs and information utilization of administrative staff, Information in decision making theories, Decision making, and Information use in decision making.

Sources of Information: According to Delgadilo and Lynch (1999), information source is a source of information for somebody, i.e. anything that might inform a person about something or provide knowledge to somebody. Information sources may be observations, people, speeches, documents, pictures and organizations. They may be primary sources, secondary sources, tertiary sources. Primary sources of information are sources that provide first hand information or direct evidence concerning a topic under study. Often these sources are created at the time when the events are occurring. According to Edwards (2001), secondary sources of information are information sources that interpret and analyze primary sources. These sources are one or more steps removed from the event. Secondary sources are materials that digest, analyze, evaluate and interpret information contained within primary sources or other secondary sources. Tertiary sources of information are sources that compile or digest other sources. Tertiary sources are not considered to be acceptable material on which to base academic research. Tertiary sources of information list, compile, digest or index primary or secondary sources. It tends to be more focused on the 
identification of scholarly work than the content itself. Tertiary source is a compilation of primary and secondary sources. There are several types of tertiary sources of information which includes dictionaries, encyclopedias and bibliographies. One should identify which source to consult to obtain reliable information.

Information Needs and Information Utilization of Administrative Staff: Information need involves the desire to locate and obtain information in order to satisfy both a conscious and an unconscious need. Information needs are related to but are simply different from requirements for information. According to Kulthau (1991), information need is often understood in information science as evolving from a vague awareness of something missing and as culminating in locating information that contributes to understanding and meaning. According to Chen and Hermon as cited in Popoola (2006), individuals, organizations or governments often find themselves where they must make decisions, answer questions, locate facts, solve problems and information must be given and transferred by an individual or by some source to provide the solution. An effective utilization of information by administrative staff facilitates easy and quick decision making effectiveness in the university system. According to Kirk (2002), information utilization involves the development of documents in a variety of forms and formats which includes paper and reports, training manuals and action plans. Information utilization has evidence to show that it has been used (utilized). Bates (2005) asserted that the most information sources used are generally those sources that are close by, have high standard, easy to use, available at low cost and which the seeker is used to, in this case, the administrative staff.

Information in Decision Making: Fabunmi and Erwat (ab. 2007), in an undated article on the effectiveness of decision making of administrative staff in tertiary institutions in Nigeria, disclosed "that information acquisition and information management capacities whether taken separately or jointly make significant contributions to the decision-making effectiveness of administrators in tertiary institutions" in Nigeria. So, information is a vital tool that should be taken seriously in decision making processes, be it in an institution or in an organization. The traditional study of decision making has taken a linear approach to policy making, whereby collecting information precedes a clear-cut decision in the logical sequence of actions. Studying the role of information in decisions making requires expanding the concepts of 'information' and 'decision'. While it is possible to study the impact of a well-defined piece of information on a single discrete decision, the reality of its application in organizational reality is more complex. One reason is that decisions are seldom discrete, and is therefore hard to determine when and where a decision is actually taken. The intensity of decisions may not be known until the application of that decision. Looking backwards decision has been taken, but at the time it was taken, nobody was aware of it, it was not seen as a serious matter. Processing of information does not always happen within a clearly defined organizational routine (Moynihan and Pandey 2005).

Decision making: According to Cole (2004), many steps are involved in efficient decision-making that require the input of information at different stages of the process, as well as a feedback. Decisions can be quick or slow, large or small, easy or risky but they are vital components of success in an organization. The role of information in decision making cannot be overemphasized. Effective decision making demands accurate, timely and relevant information. Decision making is performing of a task, that of making a particular decision, taking a side that would affect an institution positively or negatively. Where the relevant information required for planning are not available at the appropriate time, there is bound to be poor planning, inappropriate decision making, poor priority of needs, defective programming or scheduling of activities. Decision making is the accomplishment of a decision task, where decision influences are assessed and where a decision choice is made. Without making decisions, the university system will not be efficient and effective in its operation. There are different types of decisions classified according to the kind of decision taken, the impact of such decisions on the individual, the styles of decision making and the situation in which the decisions are being made (Debopriya, 2011). Based on the nature of the decisions, decision making may be of the following types namely: irreversible, reversible, delayed, quick decisions, experimental, trial and error, and conditional. Each has its effect. There should be a process to be followed in decision making. The entire decision making process is dependent upon the right information being available to the right people at 
the right time (Yadav and Khazanchi, 1992). Sambamurthy and Zmud (1999) argue that while information requirements of decision makers are task dependent as well as influenced by situational and individual characteristics, decision makers too often do not understand their information requirements, and demand too little or too much information. The planning and decision-making function involves analyzing the current situation, identifying goals, deriving objectives from goals, formulating policies, developing effective strategies or courses of action, and allocating resources. All of these activities undertaken by administrators involve a focus on decision-making and problem-solving. In all of them, information is paramount!

\section{Methodology}

The descriptive Survey design was used in this research. The use of structured questionnaire was adopted to elicit the views of the administrative staff in the Federal University of Agriculture, Abeokuta (FUNAAB). The study population was the senior non-teaching staff of the university. Total enumeration of the administrative staff (137) was involved. These were the total number of non-secretarial staff of the university during the time of this research. The research instrument used was the questionnaire. The questionnaire was subdivided into Sections A, B, C and D. Section A contains demographic information of the respondents. Section B had questions on the sources of information consulted by the administrative staff with "Yes, No, Don't know" rated alternative answers. Section C sought responses on the respondents' reasons for information use. Three alternative valued responses of "Yes, Not Sure, and No" were given; the last section, Section D, had questions on the perceived influence of information use on decision making of the administrative staff. The response format was same as in section $C$.

Data Collection: The copies of the questionnaire were distributed by the researchers individually and retrieved after they had been filled by the respondents. A total number of 137 questionnaires were administered to administrative staff of Federal University of Agriculture, Abeokuta in Ogun State out of which only 102 copies were filled and returned. Two were void and only 100 returned copies were used.

Data Analysis and Interpretation: Collected data was analyzed using discrete figures, frequency tables and simple percentages to test the significant differences between variables and their frequencies. The analysis was based on a total of 100 valid returned questionnaires. The percentage of copies of questionnaire retrieved was $74 \%$.

Demographic Characteristics: Seventy four percent (74\%) of the respondents were males and 26\% were females. Respondents of age group 25-34 years were 61\%, age group 35-44 years were 29\% and age group 45-54 were $10 \%$. Figure 1 showed the distribution of the respondents by duration in the present post. Fortyfive percent (45\%) of the respondents have been administrative staff for less than 1 year, $25 \%$ of respondents within 2-5 years, 27\%; 6-10 years and 3\% of the administrative work force have worked for more than 10 years in the institution. The demography showed that majority of the administrative staff of Federal University of Agriculture, Abeokuta was males and young (25-34 years) who were newly appointed to that position since $45 \%$ of them have not worked beyond one year. Since only $3 \%$ of the administrative staff had worked beyond 10 years, it implied that the institution has a systematic way of promoting their staff.

\section{Figure 1: Distribution of Respondents by Time Employed}

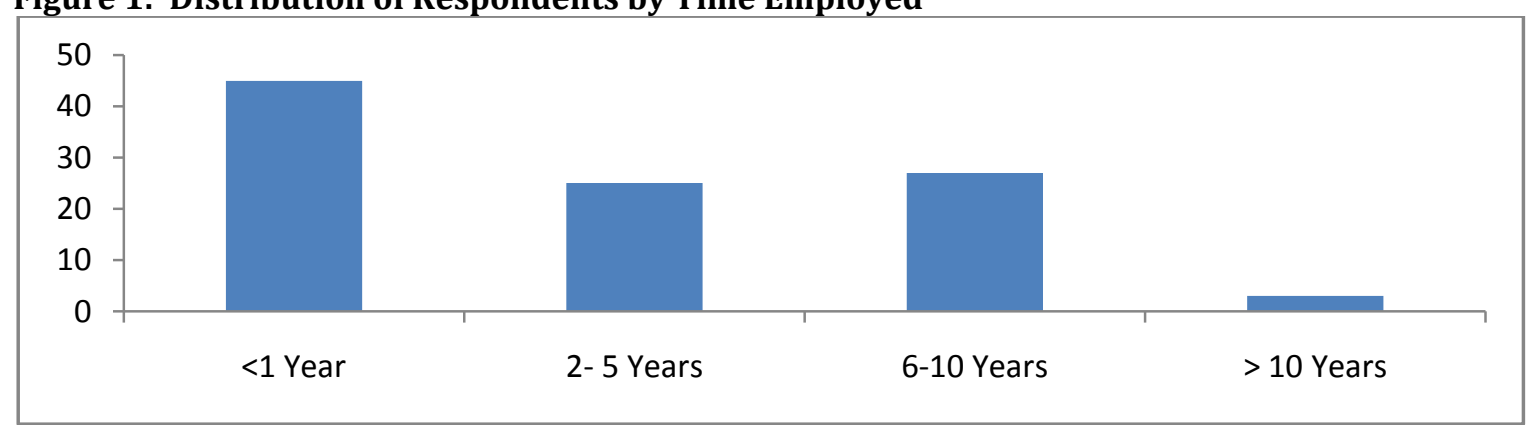




\section{Analysis of Research Questions}

Research Question 1: What were the Sources of Information used by administrative staff of Federal University of Agriculture, Abeokuta?

Table 1: Sources of Information Consulted by the Administrative Staff.

\begin{tabular}{llll}
\hline Sources of information & Yes & No & Don't know \\
\hline Internal Memo & $87(87 \%)$ & $6(6 \%)$ & $7(7 \%)$ \\
Minutes of meeting & $86(86 \%)$ & $7(7 \%)$ & $7(7 \%)$ \\
Schedules of meeting & $81(81 \%)$ & $10(10 \%)$ & $9(9 \%)$ \\
Past conference papers & $77(77 \%)$ & $16(16 \%)$ & $7(7 \%)$ \\
Staff bulletin & $79(79 \%)$ & $13(13 \%)$ & $8(8 \%)$ \\
Voice mail messages & $50(50 \%)$ & $38(38 \%)$ & $12(12 \%)$ \\
Staff records & $75(75 \%)$ & $17(17 \%)$ & $8(8 \%)$ \\
Payroll & $60(60 \%)$ & $33(33 \%)$ & $7(7 \%)$ \\
Subject books & $60(60 \%)$ & $33(33 \%)$ & $7(7 \%)$ \\
Journals & $67(67 \%)$ & $26(26 \%)$ & $7(7 \%)$ \\
Dictionaries & $82(82 \%)$ & $10(10 \%)$ & $8(8 \%)$ \\
Encyclopedia & $78(78 \%)$ & $13(13 \%)$ & $9(9 \%)$ \\
\hline
\end{tabular}

From Table 1, internal memo (87\%), minutes of meetings $(86 \%)$, dictionaries $(82 \%)$, and schedule of meetings $(81 \%)$ were the major sources of the respondents' information in making decisions, and in that order of importance. Following in importance were staff bulletin (79\%), encyclopedia ((78\%), past conference papers (77\%), and staff records (75\%) all these sources scored over $70 \%$ rating. The least in importance as a source of information for decision making were voice mail messages $(60 \%)$ though with a high rate of "undecided" opinions (12\%), followed by payroll and subject books each with $60 \%$. The priorities were right because one cannot take decision on unconfirmed and unreliable source like the voice mail. Subject books and payroll documents could be trusted to be used in making decisions based on their contents because they are reliable sources.

Research Question 2: For what reasons do the administrative staff of Federal University of Agriculture, Abeokuta use information?

Table 2: Reasons for Information Use

\begin{tabular}{llll}
\hline Reasons for information use & Yes & Not Sure & No \\
\hline I consult travel guide before embarking on a journey by road. & 72 & 13 & 15 \\
& $(72 \%)$ & $(13 \%)$ & $(15 \%)$ \\
I do consult a travel guide to know the departure and arrival time of & 79 & 13 & 8 \\
airlines when embarking on a journey & $(79 \%)$ & $(13 \%)$ & $(8 \%)$ \\
Check lists of intended events before scheduling an appointment & 85 & 8 & 7 \\
& $(85 \%)$ & $(8 \%)$ & $(7 \%)$ \\
I look carefully at a list of intended events before calling up a meeting & 86 & 7 & 7 \\
of other members of staff. & $(86 \%)$ & $(7 \%)$ & $(7 \%)$ \\
The work schedules of other members of staff before setting up a & 80 & 8 & 12 \\
meeting. & $(80 \%)$ & $(8 \%)$ & $(12 \%)$ \\
Total population of existing students in the University is considered & 75 & 17 & 8 \\
before new students are admitted into the school & $(75 \%)$ & $(17 \%)$ & $(8 \%)$ \\
Overall population of existing staff is checked before recruiting new & 84 & 9 & 7 \\
staff & $(84 \%)$ & $(9 \%)$ & $(7 \%)$
\end{tabular}




\begin{tabular}{llll} 
The overall performance of new and existing staff is considered before & 80 & 12 & 8 \\
they are sent for training & $(80 \%)$ & $(12 \%)$ & $(8 \%)$ \\
Members of staff are queried after they must & 75 & 16 & 9 \\
have been reported once by a superior staff & $(75 \%)$ & $(16 \%)$ & $(9 \%)$ \\
Staff job would be terminated after several warnings from superior & 79 & 11 & 10 \\
staff & $(79 \%)$ & $(11 \%)$ & $(10 \%)$ \\
I do interact with vendors to enquire the actual price of office & 76 & 16 & 8 \\
equipments before purchasing it & $(76 \%)$ & $(16 \%)$ & $(8 \%)$ \\
I do look carefully at the calendar whener I want to fix an & 84 & 9 & 7 \\
appointment & $(84 \%)$ & $(9 \%)$ & $(7 \%)$ \\
\hline
\end{tabular}

From Table 2 it was clear that the respondents consulted information sources before taking various decisions on what steps to follow. Decisions were not taken by guess work. For examples, they consulted travel guides to know the departure and arrival time of airlines when embarking on a journey, lists of intended events were checked before scheduling an appointment, lists of intended events were checked before scheduling a meeting, total population of existing students in the university were considered before new students were admitted into the University, and the overall population of existing staff were considered before recruiting new staff. These were evidences that information was sought and used in decision making of the staff.

Research Question 3: What influence does information use have on decision making process of the administrative staff of Federal University of Agriculture, Abeokuta?

Table 3: Perceived Influence of Information Use on Decision Making

\begin{tabular}{llll}
\hline $\begin{array}{l}\text { Perceived Influence of information use on decision } \\
\text { making }\end{array}$ & Yes & No & $\begin{array}{l}\text { Don't } \\
\text { Know }\end{array}$ \\
\hline $\begin{array}{l}\text { Does information use affect the decision making of } \\
\text { administrative staff? }\end{array}$ & $83(83 \%)$ & $8(8 \%)$ & $9(9 \%)$ \\
$\begin{array}{l}\text { Is information a criterion for solving administrative } \\
\text { issues? }\end{array}$ & $86(86 \%)$ & $8(8 \%)$ & $6(6 \%)$ \\
$\begin{array}{l}\text { Is there any relationship between information use and } \\
\text { decision making? }\end{array}$ & $86(86 \%)$ & $8(8 \%)$ & $6(6 \%)$ \\
\hline
\end{tabular}

From Table 3, 83\% of the respondents admitted that information use affected the decision making of administrative staff, $8 \%$ of the respondents did not admit that information use affected the decision making of Administrative staff and $9 \%$ of the respondents did not know if information use affected the decision making of administrative staff of the university. On solution to administrative issues, $86 \%$ of the respondents admitted that information was a criterion for solving administrative issues, $8 \%$ did not admit while $6 \%$ were not sure. $86 \%$ of the respondents admitted that there was a relationship between information use on decision making of administrative staff, $8 \%$ did not admit any relationship between information use on decision making and $6 \%$ of the respondents did not know if there was any relationship between information use on decision making of administrative staff or not.

Discussion of Findings: Findings from the research revealed that majority of administrative staff consulted resources before making decisions especially internal resources. This confirmed the conclusion drawn by Bates (2005) that most of the information sources consulted by information users are generally those sources that are close by. Majority of the administrative staff do not take any decision or action without having reasons to substantiate their action. The findings also revealed that there was a perceived influence of information use on decision making process of administrative staff which confirms the conclusion drawn from a study carried out by Gibson (2001) who stated that some theories of group decision making focus on teams' need to use information fully and effectively to reach high quality decisions. 


\section{Conclusion}

Most of the administrative staff of Federal University of Agriculture, Abeokuta was fully aware of how the use of information can help in making administrative decisions and those who were unaware were few. The male respondents were more which shows that the population of male Administrative Staff was high. The most frequently consulted information sources were internal memo, minutes of meetings, schedules of meetings, past conference papers, staff bulletin, staff records, and dictionaries. The least frequently used information source was the voice mail. From this study, the administrative staff of Federal University of Agriculture, Abeokuta was conscious of the significance of the use of information in making administrative decisions in order to achieve the goals and objectives of the University. It has been confirmed, by this research, that the use of information plays an important role in the decision making of administrative staff of Federal University of Agriculture, Abeokuta.

Recommendations: The use of voice mail messages by administrative staff should be encouraged, but the sender must mention his/her name in full. Signed text messages could be an alternative since both could come from the same device. This is pertinent because individuals could be reached wherever they are.

\section{References}

Anderson, A. (2013). Bad Decision-Making Processes That Affect Employees Badly. http://www.ehow.com/info_8352165_bad-processes-affect-employees-badly.html\#ixzz2HBwrGP2t. Cite visited January 6, 2013.

Birnbaum, R. (1998). How colleges work. The Cybernetics of Academic Organization and Leadership. San Francisco, CA: Jossey-Bass.

Bates, M .J. (2005). An introduction to metatheories, theories and models. In K. E. Fisher, S. Erdelez \& L. McKechnie. (EF). Theories of Information Behavior (pp. 1-24). ASIST Monograph Series, Medford, New Jersey: Information Today, Inc.

Cole, G. (2004). Management Theory and Practice, $6^{\text {th }}$ ed. London: Thomas Learning.

Debopriya, B. (2011). Home topics featured articles: Types of Decisions.

Delgadillo, R. \& Lynch, B. (1999). Future historians: Their quest for information. College and Research Libraries, 245-259

Edwards, H. M. (2001). Riemann's Zeta Funct. Mineola, New York: Courier Dover Publications http://books.google.com/primary.

Fabunmi, M. \& Erwat, A. (ab.2007). The contribution of information acquisition and management capacity to administrators' decision-making effectiveness in tertiary institutions in South-Western Nigeria. http://www3.airweb.org/webrecordings/publications/africanreview/Fabunmi\%20and\%20Erwat.p df. Site visited January 6, 2013.

Federal University of Agriculture. (2012). Federal University of Agriculture, Abeokuta. www.unaab.edu.ng Site visited June 15, 2012.

Gibson, C. \& Zellmer-Bruhn, M. (2001). Metaphors and meaning: An intercultural analysis of the concept of teamwork. Administrative Science Quarterly, 46, 274-303.

Goodman, S. K. (1993). Information needs for management decision. Making Records Management Quarterly. Retrieved October 1, 2011.

Kirk, J. (2002). Theorizing Information Use: Managers and Their Work. Unpublished Doctoral Dissertation, University of Technology, Sydney, Australia.

Kuhlthau, C. (1991). Inside the search process: Information seeking from the user's perspective. Journal of the American Society for Information Science, 42, 361-71.

Moynihan, D. P. \& Pandey, S. K. (2005). Testing how management matters in an era of 0government by performance management. Journal of Public Administration Research and Theory, 15(3), 422-39.

Parree, R. (2011). It is better to make a Bad Decision than to make no Decision at All. http://www.edc4it.com/2011/05/11/it-is-better-to-make-a-bad-decision-than-to-make-nodecision-at-all/. Site visited January 6, 2013. 
Popoola, S. O. (2006). Influence of Information Availability and Utilization on Decision-Making of Managers in Large-Scale Manufacturing Industries in Nigeria. Ibadan: University of Ibadan.

Rey, S. (2008). Is a wrong decision better than no decision? http://www.linkedin.com/answers/management/change-management/MGM_CMG/3236243638752

Sambamurthy, V. \& Zmud, R. W. (1999). Arrangements for information technology governance: A theory of multiple contingencies. In MIS Quarterly, 23(2), 261-290.

Silviablue (2009). Is Making a Bad Decision Better Than Making no Decision at All? http://www.studymode.com/essays/Is-Making-A-Bad-Decision-Better-257153.html. Site visited January 6, 2013.

Yadav, S. D. \& Khazanchi, D. (1992). Subjective understanding in strategic decision making, decision support systems 8 www.citeseerx.ist.psu.edu/showciting?cid=4713044. Site visited July 24, 2012. 